\title{
Manajemen Pengendalian Diabetes Mellitus melalui Peningkatan Health Literacy Diabetes
}

\author{
Indah Restika $\mathrm{BN}^{1^{*}}$, Yusran Haskas ${ }^{2}$, Indra Dewi ${ }^{3}$ \\ 1*. Universitas Hasanuddin, Jl. Perintis Kemerdekaan KM.10,, Kota Makassar, Indonesia, 90245 \\ 2. STIKES Nani Hasanuddin Makassar, Jl. Perintis Kemerdekaan VIII, No. 24, Kota Makassar, Indonesia, 90245 \\ 3. STIKES Nani Hasanuddin Makassar, Jl. Perintis Kemerdekaan VIII, No. 24, Kota Makassar, Indonesia, 90245 \\ *e-mail: indahrestika93@gmail.com
}

\begin{abstract}
Abstrak
Prevalensi diabetes mellitus diseluruh dunia terus meningkat, diprediksikan pada tahun 2030 penderita diabetes mellitus mencapai 550 juta orang, ini setara dengan sekitar tiga kasus baru setiap 10 detik, atau hampir 10 juta per tahun. Peningkatan terbesar akan lebih dominan terjadi di negara berkembang. Pengelolaan diabetes harus dibicarakan sebagai terapetik individual antara pasien dan keluarganya dan pasien harus menerima perawatan medis secara terkoordinasi dan integrasi dari tim kesehatan, sehingga keluarga menyadari pentingnya keikutsertaan dalam perawatan penderita diabetes melitus agar kadar gula darah penderita dapat terkontrol dengan baik. Metode yang dilakukan adalah memberikan edukasi terprogram dan pendampingan serta control gula darah yang dilaksanakan dalam periode 3 bulan. Hasil pelaksanaan pengabdian masyarakat ini mengindikasikan kemampuan pengelolan penyakit diabetes oleh diabetes menjadi semakin baik serta adanya perbedaan kadar glukosa darah sebelum dan setelah dilakukan memberikan edukasi terprogram dan pendampingan serta control gula darah.
\end{abstract}

Kata Kunci : Diabetes Mellitus, Health Literacy, Edukasi

\section{Pendahuluan}

Prevalensi diabetes mellitus diseluruh dunia terus meningkat, diprediksikan pada tahun 2030 penderita diabetes mellitus mencapai 550 juta orang, ini setara dengan sekitar tiga kasus baru setiap 10 detik, atau hampir 10 juta per tahun. Peningkatan terbesar akan lebih dominan terjadi di negara berkembang. Prevalensi diabetes mellitus disetiap negara bervariasi. Pada tahun 2035, Cina merupakan negara tertinggi yang prevalensi diabetes mellitusnya mencapai 142,7 juta, selanjutnya India dengan prevalensi 109 juta, Amerika Serikat 29,7 juta. Indonesia menempati urutan ke sembilan dengan prevalensi DM mencapai 11,8 juta (Whiting, Guariguata, Weil, \& Shaw, 2011).

Health literacy yaitu kemampuan seseorang untuk memperoleh, memproses, mmemahami, dan mengkomunikasikan tentang informasi yang terkait dengan kesehatan yang diperlukan untuk membuat suatu keputusan tentang kesehatan (Zuercher, Diatta, Burnand, \& Peytremann-Bridevaux, 2017). Health literacy terdiri dari keaksaraan fungsional, komunikasi dan kritis serta memiliki urutan kesulitan yang meningkat. Keaksaraan fungsional mengacu pada keterampilan membaca dan menulis; keaksaraan komunikatif mengacu pada kemampuan untuk mengekstrak makna dari berbagai sumber informasi dan berbagi informasi; dan keaksaraan kritis berkenaan dengan kemampuan untuk menganalisis informasi secara kritis sebelum menerapkannya dalam pengambilan keputusan (Bailey et al., 2014). Semakin meningkatknya fokus pada perawatan yag berpusat pada pasien yang mengalami penyakit kronis, helath literacy menjadi aspek yang penting untuk di pertimbangkan (Zuercher et al., 2017).

Menurut Squellati, R (2010) keterampilan health literacy diperlukan untuk berdialog dan berdiskusi, membaca informasi kesehatan, menafsirkan grafik, membantu individu dalam membuat keputusan terkait studi penelitian, menggunakan alat medis untuk perawatan kesehatan pribadi atau keluarga seperti menghitung waktu atau dosis obat, ataupun keputusan terkait masalah kesehatan dan lingkungan. Pada individu yang berusia lanjut, level health literacy yang dimilikinya semakin rendah. Menurut Comings J, Reder S, Sum A. (2001) health literacy yang rendah dapat mengakibatkan pasien kesulitan dalam menjalani proses perawatan yang efektif. Selain itu, health literacy yang rendah juga di kaitkan dengan hasil kesehatan yang buruk (C. et al., 2013) hal ini dapat mengakibatkan disparitas kesehatan.

Terdapat model teoritis yang menjelaskan jalur hubungan dampak rendahnya health literacy terhadap disparitas kesehatan yaitu menurunnya kemampuan mengakses dan menggunakan perawatan medis karena individu dengan health literacy yang rendah akan mengalami kesulitan dalam menggunakan system perawatan kesehatan, meningkatnya beban stress diakibatkan meningkatkan tantangan dalam kehidupan sehari-hari dan kemampuan diri dalam manajemen penyakit, serta penurunan efikasi diri yaitu kemampuan individu mengontrol hidup dan lingkungannya (Saha, 2006).

Perbedaan level health literacy juga terdapat pada pasien yang menderita DM tipe I dan DM tipe II. Hasil studi literatur menunjukan, pasien dengan DM Tipe II memiliki level health literacy yang lebih tinggi dari pasien DM Tipe I. Perbedaan ini berkaitan dengan perbedaan etiologi penyakit ini, penderita DM tipe II yang memiliki telah 
pengetahuan yang baik tentang penyakit tersebut dapat memiliki level health literacy yang baik pula. Menurut Johnson (1998) Secara global diabetes melitus tipe 1 tidak begitu umum, hanya kira-kira 10- 20\% dari semua penderita diabetes melitus yang menderita diabetes melitus tipe 1 . Diabetes melitus tipe 1 ini biasanya bermula pada saat kanak-kanak dan puncaknya pada masa akil baliq atau remaja. Biasanya penderita diabetes melitus tipe 1 mempunyai berat badan yang kurus. Sedangkan Diabetes melitus tipe 2 biasanya didiagnosa setelah berusia 40 tahun dan $75 \%$ individu dengan diabetes melitus tipe 2 adalah obesitas atau dengan riwayat obesitas. Penyakit diabetes melitus tipe 2 biasanya terjadi pada usia dewasa yang berusia menengah atau lanjut. Di Indonesia, sekitar 95\% kasus diabetes melitus adalah diabetes melitus tipe 2, yang cenderung disebabkan oleh faktor gaya hidup yang tidak sehat (Moore, 1997). Menurut Powell, Hill, \& Clancy, (2007) health literacy yang rendah secara bermakna dikaitkan dengan kontrol glikemik yang buruk pada penderita DM tipe II.

Jika di tinjau dari tingkat pendidikan, terdapat pengaruh yang signifikan dalam linearitas arah yang positif antara tingkat pendidikan dengan level health literacy dimana semakin tinggi tingkat pendidikan maka semakin baik health literacynya. Menurut Bailey et al.,(2014) health literacy yang rendah lebih banyak dimiliki oleh individu dengan tingkat pendidikan yang terbatas. Meskipun health literacy yang rendah dapat ditemukan di setiap segmen populasi, terdapat kelompok-kelompok yang lebih rentan memiliki level health literacy yang rendah salah satunya yaitu kelompok individu dengan tingkat pendidikan yang terbatas, individu yang menggunakan bahasa inggris sebagai bahasa kedua, serta kelompok yang berpendapatn rendah (Kutner, M., Greenberg, E., Jin, Y.,\& Paulsen, C, 2006).

Pada individu dengan indeks massa tubuh yang melebihi normal (IMT $\geq 25$ ), level health literacynya semakin rendah. Schillinger D, Grumbach K, Piette J, et al. (2002) mengemukakan bahwa literasi kesehatan yang rendah dikaitkan dengan pengetahuan tentang penyakit dan strategi manajemen diri yang buruk, status kesehatan yang buruk, ketidakpatuhan terhadap pengobatan, peningkatan risiko rawat inap mencapai 30\% hingga 50\%, serta biaya perawatan kesehatan tahunan yang lebih tinggi. Keseluruhan artikel yang direview yaitu Zuercher et al., (2017); (Hussein, Almajran, \& Albatineh, (2018); Jayasinghe et al., (2016); menunjukan kesamaan hasil bahwa individu dengan indeks massa tubuh yang melebihi normal memiliki level health literacy yang rendah.

Melihat empirismi bahwa health literacy berkontribusi dalam kondisi kesehatan pasien maka diperlukan upaya peningkatan health literacy pasien melalui edukasi terstruktur dalam prigam pengabdian masyarakat yang dilaksanakan di Kelurahan Katimbang Kecamatan Biringkanaya Kota Makassar.

\section{Metode Pelaksanaan}

Kegiatan pengabdian kepada masyarakat ini berlokasi di RW 001 \& RW 002 Kelurahan Katimbang Kecamatan Biringkanaya Kota Makassar. Bertujuan untuk mengetahui tingkat health literacy diabetes di Kelurahan Katimbang melalui survey menyeluruh serta untuk meningkatkan health literacy masyarakat diabetes melalui edukasi terstruktur tentang manajemen pengendalian diabetes mellitus. Dalam program pengabdian masyarakat ini, selain peserta yang sejumlah 42 orang diberikan edukasi terstruktur, juga dilakukan pendampingan selama 3 bulan dan pemeriksaan kesehatan gratis untuk control gula darah pada peserta. Pengukuran kadar glukosa darah (GDS) dengan menggunakan glucometer yang di laksanakan oleh pelaksana pengabdian beserta dibantu oleh petugas kesehatan setempat.

\section{Hasil}

Pemberian edukasi terstruktur mempunyai target untuk meningkatkan health literacy diabetes yang secara langsung diindikasikan berdampak pada peningkatan kemampuan diabetes dalam manajemen pengendalian diabetes mellitus.

Tabel 1. Distribusi frekuensi

\begin{tabular}{|c|c|c|c|}
\hline No & Karakteristik Responden & $\mathrm{n}$ & $\%$ \\
\hline \multirow{4}{*}{1} & Jenis Kelamin & & \\
& Perempuan & 37 & 88.1 \\
& Laki-laki & 5 & 11.9 \\
\hline & Tingkat Pendidikan & & \\
& SD & 8 & 19.1 \\
& SMP & 9 & 21.4 \\
& SMA & 15 & 35.7 \\
& PT & 10 & 23.8 \\
\hline & Pekerjaan & & \\
& PNS & 7 & 16.7 \\
& Wiraswasta & 7 & 19.0 \\
& IRT & 20 & 47.6 \\
\hline \multicolumn{2}{|c|}{ Pensiunan } & 42 & 100.0 \\
\hline
\end{tabular}


Tabel 1. Menunjukkan bahwa distribusi peserta kegiatan pengabdian kepada masyarakat ini lebih dominan berdasarkan jenis kelamin yaitu perempuan sebesar $88.1 \%$, tingkat pendidikan terakhir yaitu SMA sebesar $35.7 \%$, dan pekerjaan sebagai pensiunan sebesar $47.6 \%$.

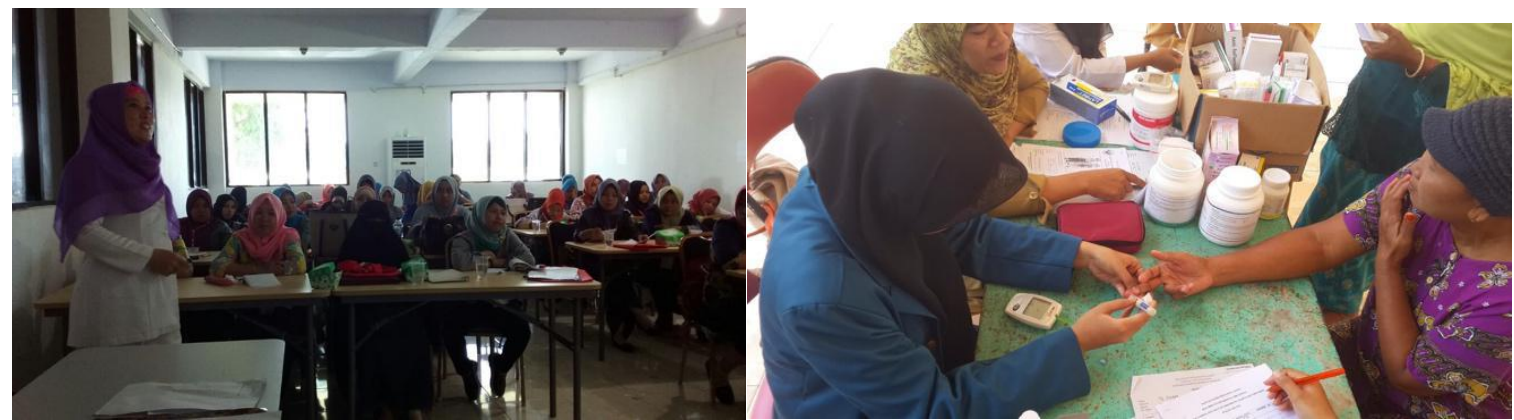

Gambar 1. Dokumentasi kegiatan pemberian edukasi terstruktur dan pemeriksaan GDS yang diikuti oleh peserta pengabdian kepada masyarakat di RW 001 \& RW 002 Kelurahan Katimbang.

Tabel 2. Hasil Uji T Dependen Kadar Glukosa Darah Sewaktu Diabetes pre-edukasi(september) dan post-edukasi terstruktur yang didampingi selama 3 bulan (desember) $(n=42)$

\begin{tabular}{|c|c|c|c|c|c|c|c|c|c|c|}
\hline \multirow{2}{*}{ No } & \multirow{2}{*}{$\begin{array}{l}\text { Edukasi } \\
\text { terstruktur }\end{array}$} & \multirow{2}{*}{ Mean } & \multirow{2}{*}{$\delta$} & \multirow{2}{*}{$\mathrm{SE}$} & \multicolumn{4}{|c|}{ Perbedaan } & & \multirow{2}{*}{$\begin{array}{c}\rho- \\
\text { value }\end{array}$} \\
\hline & & & & & CI $95 \%$ & Mean & $\delta$ & $\mathrm{SE}$ & & \\
\hline 1 & Sebelum & 126.14 & 64.47 & 9.94 & \multirow{2}{*}{$\begin{array}{c}0.56- \\
17.91\end{array}$} & \multirow{2}{*}{9.23} & \multirow{2}{*}{27.83} & \multirow{2}{*}{4.29} & \multirow{2}{*}{2.15} & \multirow{2}{*}{0.037} \\
\hline 2 & Setelah & 116.90 & 42.53 & 6.56 & & & & & & \\
\hline
\end{tabular}

Tabel 2. menunjukkan bahwa hasil uji t-dependen terlihat rata-rata perbedaan antara GDS pre edukasi dan post edukasi untuk meningkatkan health literacy diabetesi adalah sebesar 9.23, artinya ada penurunan kadar GDS setelah dilakukan senam DM dengan rata-rata penurum sebesar $9.23 \mathrm{mg} / \mathrm{dL}$. Hasil perhitungan nilai t adalah sebesar 2.15 dengan $\rho$-value 0.037, artinya ada perbedaan yang signifikan antara rata-rata kadar GDS sebelum dan setelah intervensi.

\section{Pembahasan}

Hasil pengabdian kepada masyarakat menunjukkan bahwa ada peningkatan health literacy diabetes setalah diberikan edukasi terstruktur dan pendampingan yang di buktikan dengan adanya perbedaarn rerata GDS penderita DM sebelum dan sesudah program edukasi dan pendampingan untuk penguatan health literacynya. Berarti pelatihan ini dapat meningkatkan pengetahuan peserta pengabdian dalam manajemen diabetes melitus sehingga dapat mengubah perilaku penderita DM dalam mengendalikan penyakitnya. Tujuan dari program ini agar penderita DM dapat melakukan manajemen penyakit DM dengan baik serta mengontrol kadar gula darahnya tetap normal sehingga penyakit diabetesnya tetap terkendali. Kadar gula darah adalah jumlah atau konsentrasi glukosa yang terdapat dalam darah. Penderita DM yang tidak dapat memproduksi insulin dengan cukup akan menyebabkan peningkatan konsentrasi glukosa dalam darah, sehingga terkendalinya kadar gula darah yang baik dan optimal dapat mencegah terjadinya komplikasi kronik (WHO, 2015).

Sangat penting untuk senantiasa diberikan penguatan pada diabetesi agar health literacynya meningkat. Health literacy sangat bervariasi pada setiap individu, berdasarkan study literatur variabiltas level health literacy terdapat dalam berbagai dimensi dianataranya yaitu ada perbedaan level health literacy antara laki-laki dan perempuan, lansia (diatas 55 tahun) memiliki health literacy lebih rendah dibandingkan usia dibawahnya, pasien dengan DM Tipe II memiliki level health literacy yang lebih tinggi dari pasien DM Tipe I, semakin tinggi tingkat pendidikan maka semakin tinggi level health literacynya, tidak ada perbedaan level health literacy antara ras kulit putih dan ras kulit hitam, semakin tinggi tingkat pendapatan maka semakin tinggi level health literacynya, level health literacy yang tinggi sebagian besar dimiliki oleh responden yang lama menderita $<10$ Tahun, serta orang dengan indeks masa tubuh melebihi normal ( IMT $\geq 25$ ) memiliki level health literacy rendah.

Salah satu upaya yang baik untuk menangani DM agar tidak berlanjut pada komplikasi adalah pencegahan dengan melakukan perubahan gaya hidup dan pola makan. Gaya hidup dapat memperbaiki indeks massa tubuh, lingkar pinggang, tekanan darah dan glukosa darah penderita DM. Gaya hidup sehat lebih berefek pada penurunan Gula Darah Sewaktu karena terdapat perubahan pola pemilihan makanan dan minuman yang berindeks glikemik tinggi menjadi berindeks glikemik rendah, walaupun tidak terdapat perbedaan jumlah kalori per hari (Pusthika, Tjahjono, \& Nuggetsiana, 2011).

Dalam jurnal penelitian yang berjudul "Weekly lifestyle counselling improves glucose level in type 2 diabetes melitus patients" oleh Setyawati, Pusthika, and Octa (2015) ditemukan konseling gaya hidup dan modifikasi diet memperbaiki kontrol kadar gula darah pada kelompok intervensi bila dibandingkan dengan kelompok kontrol 
( $\mathrm{p}=0,002$ ), akan tetapi tidak demikian dengan IMT, LP, sistolik, diastolik, kolesterol total, trigliserida, LDL dan HDL. Efek positif seiring waktu ditemukan pada kelompok intevensi sebelum dan sesudah perlakuan. American Diabetes Association (ADA, 2010) mengemukakan bahwa perencanaan pengelolaan diabetes harus dibicarakan sebagai terapetik individual antara pasien dan keluarganya dan pasien harus menerima perawatan medis secara terkoordinasi dan integrasi dari tim kesehatan, sehingga keluarga menyadari pentingnya keikutsertaan dalam perawatan penderita diabetes melitus agar kadar gula darah penderita dapat terkontrol dengan baik.

Perilaku pengendalian DM yang baik merupakan salah satu faktor yang membuat tingkat kesembuhan penyakit DM akan menjadi lebih baik, sebaliknya apabila kurangnya perilaku pengendalian DM dapat mengakibatkan hiperglikemia dalam jangka panjang yang menjadi pemicu beberapa komplikasi yang serius baik makrovaskular maupun mikrovaskular seperti penyakit jantung, gagal ginjal, kerusakan saraf dan kebutaan. Pengendalian diabetes melitus dapat mempengaruhi kestabilan kadar gula darah seseorang, jika pengendalian diabetes buruk maka kemungkinan kadar gula darah pun akan tinggi atau tidak terkontrol begitupun sebaliknya, jika pengendalian diabetes dilakukan dengan baik maka kadar gula akan terkontrol atau mendekati kadar gula yang normal (Worang V.H.K, Bawotong J, \& Untu, 2013).

Penderita DM kurang mengetahui manfaat jika kadar gula darah terkontrol baik. Kontrol intensif untuk penderita diabetes melalui terapi nutrisi medik, olahraga dan obat-obatan sangat perlu agar gula darah terkontrol baik sehingga dapat mencegah atau menunda terjadinya komplikasi penyakit. Dokter dengan tim kesehatan perawat dan ahli gizi harus dapat memotivasi pasien serta saling bekerja sama dalam menanggulangi penyakit diabetes (Mihardja, 2009).

Menurut Soegondo (2009) ada 7 tujuan pengendalian DM yaitu: menghilangkan gejala, menciptakan dan mempertahankan rasa sehat, memperbaiki kualitas hidup, mencegah komplikasi akut dan kronik, mengurangi laju perkembangan komplikasi yang ada, mengurangi kematian dan mengobati penyakit penyerta bila ada. Untuk mengetahui kadar gula darah terkontrol, tentunya tidak dapat bergantung pada hilangnya gejala.

Melalui kegiatan terprogram dalam manajemen pengendalian diabetes pada kelompok-kelompok berisiko maka dapat menurunkan morbiditas serta mortalitas penduduk akibat diabetes mellitus. Oleh karena itu, penggalakan upaya terprogam dalam manajemen diabetes sangat disarankan untuk dilaksanakan berikesinambunga.

\section{Daftar Pustaka}

Bailey, S. C., Brega, A. G., Crutchfield, T. M., Elasy, T., Herr, H., Kaphingst, K., ... Schillinger, D. (2014). Update on Health Literacy and Diabetes. The Diabetes Educator, 40(5), 581- 604. https://doi.org/10.1177/0145721714540220

Comings J, Reder S, Sum A. (2001) Building a level playing field:the need to expand and improve the national and state adult education and literacy systems. Cambridge: National center for the study of adult learning and literacy

Hussein, S. F., Almajran, A., \& Albatineh, A. N. (2018). Prevalence of health literacy and its correlates among patients with type II diabetes in Kuwait: a population based study. Diabetes Research and Clinical Practice. https://doi.org/10.1016/j.diabres.2018.04.033

Jayasinghe, U. W., Harris, M. F., Parker, S. M., Litt, J., van Driel, M., Mazza, D., ... Wilson, J. (2016). The impact of health literacy and life style risk factors on health-related quality of life of Australian patients. Health and Quality of Life Outcomes, 14(1), 1-13. https://doi.org/10.1186/s12955-016-0471-1।

Johnson, M (1998). Diabetes Terapi dan Pencegahannya. Bandung: Indonesia Publishing House.

Kutner, M., Greenberg, E., Jin, Y.,\&Paulsen, C. (2006). The health literacy of America's adults: Results from the 2003 National Assessment of Adult Literacy. Washington, DC: U.S. Department of Education, National Center for Education Statistics (NCES) Publication No. 2006-483.

Mihardja. (2009). Faktor yang Berhubungan dengan Pengendalian Gula Darah pada Penderita Diabetes Mellitus di Perkotaan Indonesia. Maj Kedokt Indon, 59(9), 418-424.

Moore, M. C. (1997). Buku Pedoman Terapi Diet dan Nutrisi. Jakarta: Penerbit Hipocrates.

Paasche-Orlow, M. K., Schillinger, D., Greene, S. M., \& Wagner, E. H. (2006). How health care systems can begin to address the challenge of limited literacy. Journal of General Internal Medicine, 21(8), 884-887. https://doi.org/10.1111/j.1525-1497.2006.00544.x

Pusthika, I. O., Tjahjono, K., \& Nuggetsiana, A. (2011). Pengaruh Frekuensi Konseling Gizi dan Gaya Hidup terhadap Indeks Massa Tubuh, Lingkar Pinggang, Tekanan Darah, dan Glukosa Darah pada Penderita Diabetes Mellitus. Faculty of Medicine. 
Rotter, J. B. (1966). Generalized expectancies for internal versus external control of reinforcement. Psychological monographs: General and applied, 80(1),

Powell, C. K., Hill, E. G., \& Clancy, D. E. (2007). The relationship between health literacy and diabetes knowledge and readiness to take health actions. Diabetes Educator, 33(1), 144- 151. https://doi.org/10.1177/014572170629745

Saha, S. (2006). Improving literacy as a means to reducing health disparities, 97239, 893-895. https://doi.org/10.1111/j.1525-1497.2006.00546.x

Schillinger D, Grumbach K, Piette J, et al. Association of health literacy with diabetes outcomes. JAMA. 2002;288:475482.Squellati, R., (2010) Health literacy: understanding basic health information. Creat Nurse, 16(3): p. 110-4.

Soegondo, S., Soewondo, P., \& Subekti, I. (2009). Penatalaksanaan diabetes melitus terpadu. FKUI. Jakarta.

Whiting, D. R., Guariguata, L., Weil, C., \& Shaw, J. (2011). IDF Diabetes Atlas: Global estimates of the prevalence of diabetes for 2011 and 2030. Diabetes Research and Clinical Practice, 94(3), 311-321. https://doi.org/10.1016/j.diabres.2011.10.029

Worang V.H.K, Bawotong J, \& Untu, E. M. (2013). Hubungan Pengendalian Diabetes Mellitus dengan Kadar Glukosa Darah Pada Pasien Diabetes Mellitus di RSUD Manembo Nembo Bitung. ejournal Keperawatan ( e-Kp), 1(1).

Zuercher, E., Diatta, I. D., Burnand, B., \& Peytremann-Bridevaux, I. (2017). Health literacy and quality of care of patients with diabetes: A cross-sectional analysis. Primary Care Diabetes, 11(3), $233-240$. https://doi.org/10.1016/j.pcd.2017.02.003 